\title{
EFFECTS OF THERMAL MASS, VENTILATION AND GLAZING ORIENTATION ON INDOOR AIR TEMPERATURE IN BUILDINGS
}

\author{
Imre Csáky and Ferenc Kalmár ${ }^{1}$
}

\begin{abstract}
In the last years in European countries important measures were taken in order to reduce the energy need of buildings. Nevertheless the energy need for cooling of buildings is rising. In most cases, to assure the required operative temperature, air conditioning systems are installed. Consequently, in summer period the power networks of different European countries are overloaded. In order to determine the effects of glazed area orientation, air change rate and thermal mass on the indoor air temperature, at the University of Debrecen the PASSOL laboratory was built. Measurements were performed from 2009 to 2013. Using the methodology given by EN ISO 13790 the variation of indoor temperature was calculated and the theoretical values were compared with values obtained from measurements. The indoor temperature variation and the energy need for cooling was analysed for different building structures, different orientations of the glazed area and air change rates. The calculations have proven that the energy need for cooling can be reduced even to $25 \%$ of the thermal mass and the air change rate are chosen properly.
\end{abstract}

Keywords: air change, cooling energy, heat gains, indoor air temperature, thermal mass

\section{Introduction}

Buildings are built to ensure comfortable conditions for people. The required microenvironmental conditions depend on the activities performed. It was demonstrated that people perform better in closed spaces that have transparent surfaces (Leather et al., 1998; Stone, 1998). Consequently, to obtain a high level of comfort, a series of auxiliary design optimizations must be completed. Designers must optimize the area, orientation and shading of the transparent surfaces while accounting for the specific thermal, visual, acoustical and security requirements. Thermal comfort and visual conditions are strongly influenced by continually changing solar radiation. Solar radiation directly entering closed spaces through transparent surfaces is challenging to control to maintain thermal comfort limits, particularly in the summer months. The comfort needs of building occupants have risen continuously; consequently, in countries with temperate, Mediterranean or tropical climates, installed air conditioning devices have caused considerable increases in electricity consumption in the summer. Previous research has proven that in European

\footnotetext{
${ }^{1}$ Corresponding author, e-mail: fkalmar@eng.unideb.hu University of Debrecen, Faculty of Engineering, 4028 Debrecen, Ótemető u. 2-4, Hungary
} 
countries, the number and amplitude of heat waves will increase in the future (Luterbacher et al., 2004; Schär et al., 2004). Night ventilation is an energy-conscious solution that can maintain the indoor operative temperatures under the upper limits of thermal comfort intervals (Blondeau, Spérandio and Allard, 1997; Geros et al., 1999). Other researchers have analyzed the effects of passive cooling in office buildings using night ventilation coupled with ground heat exchangers (Breesch, Bossaer and Janssens, 2005; Voss et al., 2007; Pfafferott et al., 2007; Larsen and Heiselberg, 2008). Having a properly chosen and designed thermal mass is one of the conditions of the suitable operation of night ventilation (Corgnati and Kindinis, 2007; Zhou et al., 2008; Yang and Li, 2008; Shaviv et al., 2001). Finally, the heat island in large cities affects the efficiency of night ventilation (Geros et al., 2005).

Currently, the tendency is to provide large insulation thicknesses to the opaque surfaces of the building envelope. This insulation allows the heat gains and losses through the building elements to be considerably decreased; conversely, the influence of the transparent surfaces on the overall indoor environmental quality is increased due to the thicker insulation installation. The appropriate design of transparent surfaces is thus crucial to ensure that adequate indoor environmental conditions are maintained. In this paper, the indoor temperature variation in a closed space is analyzed on different summer days, considering the fluctuating thermal mass of the room and the varying orientations of the glazed area. A special experimental laboratory (PASSOL) was built to analyze the effects of the summer heat gains. It was possible to analyze the influence of different orientations of the glazed area, the effects of thermal mass and the air change rate. The analytical results were compared with the measured experimental data. Using the calculation model provided by EN ISO 13790, the indoor temperature values and energy used for cooling were determined for the hottest days of May, June, July and August. Irrespective of the transparent element orientation and the increased air change rate, higher indoor temperature values were obtained in the cases of brick and autoclaved aerated concrete structures. Lower indoor temperature values were obtained in light structures. More energy was needed for cooling, despite the lower indoor air temperature values, due to the higher air change rate, even in the case of the light structure building.

\section{Experimental setup}

At the University of Debrecen, in the Department of Building Services and Building Engineering, a special laboratory was built to analyze the effects of the summer solar gains on the internal temperature. The test room has an identical width, length and height $(2.6 \times 2.6 \times 2.6 \mathrm{~m})$. The envelope is built from prefabricated panels that are specifically used for refrigeration chambers. The overall heat transfer coefficient of panels is $0.146 \mathrm{~W} / \mathrm{m}^{2} \mathrm{~K}$ (20 cm polyurethane foam is between the inner and outer casings). The double glazed $150 \times 150 \mathrm{~cm}$ window, which was built in one of external walls at a height of $0.9 \mathrm{~m}$, has a profile with six chambers. The overall heat transfer coefficient is $1.4 \mathrm{~W} / \mathrm{m}^{2} \mathrm{~K}$, and the $g^{2}$

\footnotetext{
${ }^{2}$ solar energy transmittance of glass, [\%]
} 
value is 0.7 (the transparent area is $1.91 \mathrm{~m}^{2}$ ). On the opposite wall, a special, built-in door that is used for refrigeration chambers is installed. The flat roof is built from the same sandwich panels and is covered by aluminum tables. This test box is fixed on a special frame, which permits the rotation of the box around its own axis (Figure 1).

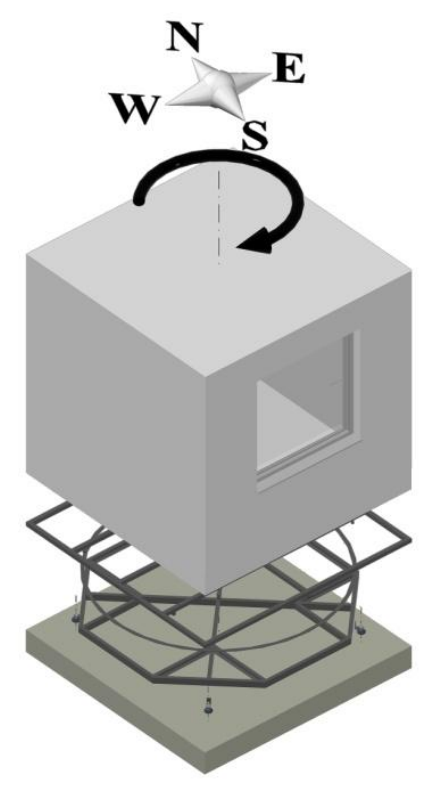

Figure 1. Test box arrangement (PASSOL).

The test box was placed on the campus of the University of Debrecen, near the city center. The shadow mask had to be determined for each orientation of the window. The geographical location of Debrecen is $47^{\circ} 31.8^{\prime} \mathrm{N}$ and $21^{\circ} 37.8^{\prime} \mathrm{E}$. The goal was to obtain an analysis of the indoor temperature variation during the hottest months of the year without using any fixed or mobile shading devices (horizontal or vertical overhangs, mobile shutters, curtains or blinds). The shading of the surrounding objects was analyzed for May, June, July and August. Using the specific sun path diagram for these months in Debrecen, it was proven that the surrounding buildings, trees and other objects create shading in the transparent area, though only for the E orientation of the window until 8:00 AM (low-angle morning sun). The window was recessed $5.0 \mathrm{~cm}$ into the wall, so the shading of the transparent area of the window was also considered.

In the middle of the room and at a height of $1.1 \mathrm{~m}$, a KIMO KH100 data logger was mounted to collect air temperature values. The sensor of the data logger was protected from the radiation of the surrounding surfaces. The measuring range of the NTC sensor type is from $-40{ }^{\circ} \mathrm{C}$ to $+120^{\circ} \mathrm{C}$. The accuracy is $\pm 0.4{ }^{\circ} \mathrm{C}$ from $+5{ }^{\circ} \mathrm{C}$ to $70{ }^{\circ} \mathrm{C}$ and $\pm 0.6{ }^{\circ} \mathrm{C}$ from $-20{ }^{\circ} \mathrm{C}$ to $+5{ }^{\circ} \mathrm{C}$. Measurement of the indoor air temperature in the test box was completed from 2009 to 2013.

The global solar radiation and hourly dry bulb temperature records from 2009 to 2013 were provided by Agro-Meteorological Observatory, Debrecen. The dry bulb temperature, relative air humidity, and wind velocity were measured at heights of $1.0 \mathrm{~m}, 2.0 \mathrm{~m}, 4.0 \mathrm{~m}$ and $10.0 \mathrm{~m}$. The temperature sensor is Pt100-1/10 with $\pm 0.1{ }^{\circ} \mathrm{C}$ accuracy. The global solar radiation was measured using a Kipp \& Zomen CMP-11 sensor with $\pm 1 \%$ accuracy. 
Applying the global solar radiation data, the direct and diffuse solar radiation were determined for both the horizontal and vertical (N, S, E, W) surfaces.

Using the solar radiation and air temperature database for each year between May and September, the heat waves were identified, and the hottest days were selected for analysis.

\section{Measurements and calculations}

Measurements of the air temperature in the test box were made for different orientations of the glazed area, different air change rates and various built-in room thermal storage capacities.

The measured air temperature values were compared with the calculated data using the simple hourly method provided by European Standard EN ISO 13790 (2008).

The calculation method uses the RC network of the heat flows, as shown in Figure 2 (EN ISO 13790:2008, 2008).

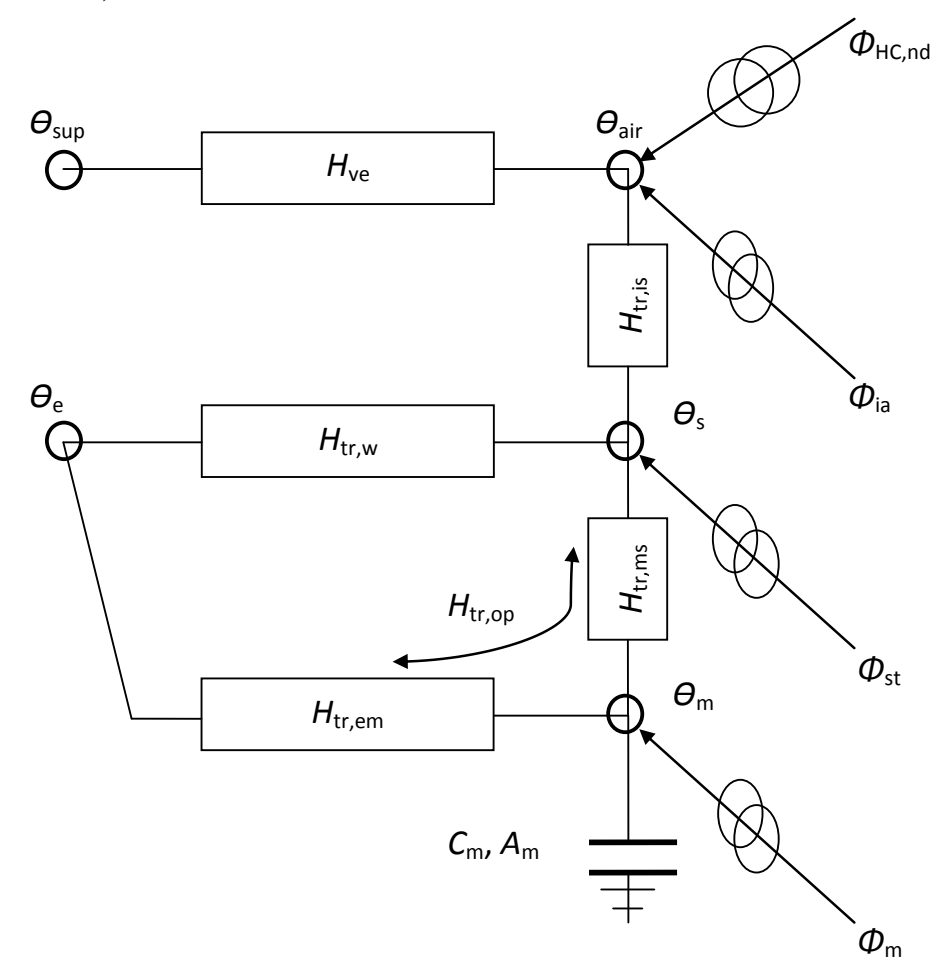

Figure 2. RC network heat flows (EN ISO 13790:2008, 2008).

Heat transfer by ventilation, $H_{v e}$, is directly connected both to the air temperature node, $\theta_{\text {air }}$, and to the node representing the supply temperature, $\theta_{\text {sup. }}$. Heat transfer by transmission is split into the window segment, $H_{t r, w}$, which is assumed to have zero thermal mass, and the remainder, $H_{t r, o p}$, which contains the thermal mass split into two parts, $H_{t r, e m}$ and $H_{t r, m s}$. Solar and internal gains are distributed over the air node, $\theta_{\text {air }}$, the central node $\theta_{\mathrm{s}}$ (a mix of $\theta_{\text {air }}$ and mean radiant temperature) and the node representing the mass of the building zone, $\theta_{\mathrm{m}}$. The thermal mass is represented by a single thermal capacity, $C_{m}$, that is located between $H_{t r, m s}$ and $H_{t r, e m}$. A coupling conductance is defined between the internal air node and the central node. The heat flow rate given by internal heat sources, $\Phi_{\text {int }}$, and solar heat 
sources, $\Phi_{\text {sol }}$, is split among the three nodes (EN ISO 13790:2008, 2008). The internal heat capacity of the building zone, $C_{m},[\mathrm{~J} / \mathrm{K}]$, was calculated for a maximum thickness of $10 \mathrm{~cm}$. The solution model is based on a Cranck-Nicholson scheme, considering a time step of one hour.

The air temperature is given by eq. (1) (EN ISO 13790:2008, 2008):

$$
\theta_{\text {air }}=\left(H_{t r, i s} \theta_{s}+H_{v e} \theta_{\text {sup }}+\Phi_{i a}+\Phi_{H C, n d}\right) /\left(H_{t r, i s}+H_{v e}\right)
$$

where $H_{\mathrm{tr}, \text { is }}$ is the transmission heat transfer coefficient, $[\mathrm{W} / \mathrm{K}] ; H_{\mathrm{ve}}$ is the ventilation heat transfer coefficient, [W/K]; and $\Phi_{\mathrm{HC}, \mathrm{nd}}-$ is the cooling need of the building, [W].

$$
\Phi_{i a}=0.5 \Phi_{\text {int }}
$$

where $\Phi_{\text {int }}$ is the heat flow rate from internal heat sources [W].

The node temperature, $\theta_{\mathrm{s}}$, is given by eq. (3) (EN ISO 13790:2008, 2008):

$\left.\theta_{s}=\left\{H_{t r, m s} \theta_{m}+\Phi_{s t}+H_{t r, w} \theta_{e}+H_{t r, 1} \mid \theta_{\text {sup }}+\left(\Phi_{i a}+\Phi_{H C, n d}\right) / H_{v e}\right]\right\} /\left(H_{t r, m s}+H_{t r, w}+H_{t r, 1}\right)$

where $\theta_{\mathrm{e}}$ is the temperature of the external environment $\left[{ }^{\circ} \mathrm{C}\right]$.

$$
\begin{aligned}
& H_{t r, 1}=\frac{1}{1 / H_{v e}+1 / H_{t r, i s}} \\
& \Phi_{s t}=\left(1-\frac{A_{m}}{A_{t}}-\frac{H_{t r, w}}{9.1 A_{t}}\right)\left(0.5 \Phi_{\mathrm{int}}+\Phi_{s o l}\right)
\end{aligned}
$$

where $A_{\mathrm{t}}$ is the area of all surfaces facing the building zone $\left[\mathrm{m}^{2}\right]$.

The coupling conductance between nodes $\mathrm{m}$ and $\mathrm{s},[\mathrm{W} / \mathrm{K}]$, is given by eq. (6) (EN ISO 13790:2008, 2008):

$$
H_{t r, m s}=h_{m s} A_{m}
$$

where $h_{\mathrm{ms}}$ is the heat transfer coefficient between nodes $m$ and $s\left[\mathrm{~W} / \mathrm{m}^{2} \mathrm{~K}\right]$ and $A_{\mathrm{m}}$ is the effective mass area $\left[\mathrm{m}^{2}\right]$.

First, the differences between the calculated and measured indoor temperature values in the test box were considered for different orientations of the glazed area, different ventilation conditions and varying thermal mass conditions. All parameters (areas, heat gains and losses, and heat transfer values) were calculated in accordance with EN ISO 13790, using 
the input meteorological data provided by the Agro-Meteorological Observatory, Debrecen. No internal gains were considered.

Test box without a transparent area, ventilation or supplementary thermal mass

After building the test box but before installing the window, measurements were taken to analyze the temperature variation in the box. Initially, a blower door test was conducted to verify the air tightness of the test box.

The blower door measurement was performed using a RETROTEC 3300 instrument. The measurements showed that there is relatively no air change rate between the test box and the external environment, even at a pressure difference (indoor versus outdoor) of $\pm 200 \mathrm{~Pa}$. The heat gains of the test box were calculated using the input temperature and solar radiation data provided by the Agro-Meteorological Observatory. The solar radiation (direct and diffused radiation) and heat gains are shown in Figure 3. As a result of these gains, the measured and calculated indoor temperature variations are presented in Figure 4.

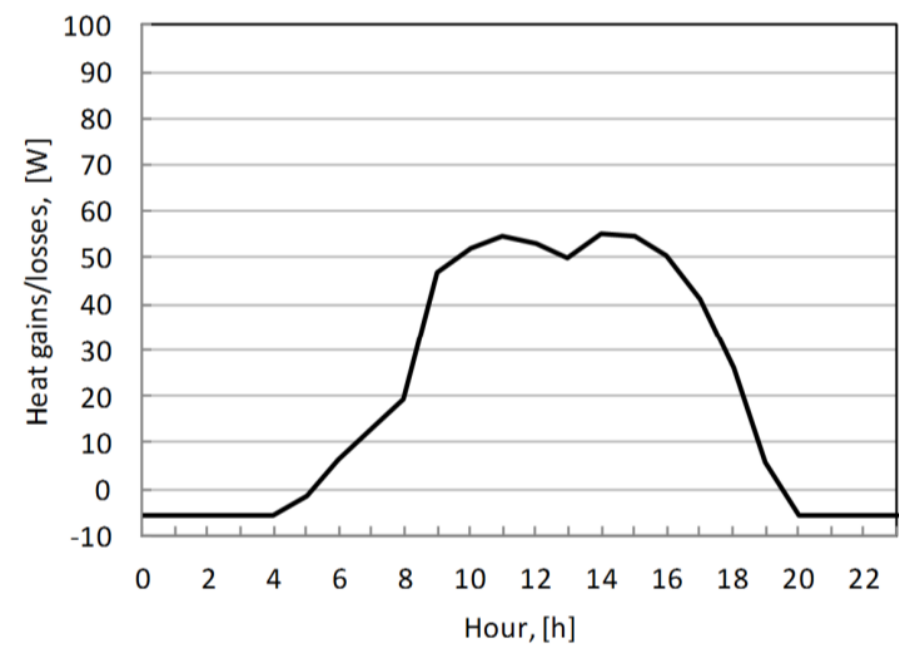

Figure 3. Heat gains and losses of the "blinded" test box.

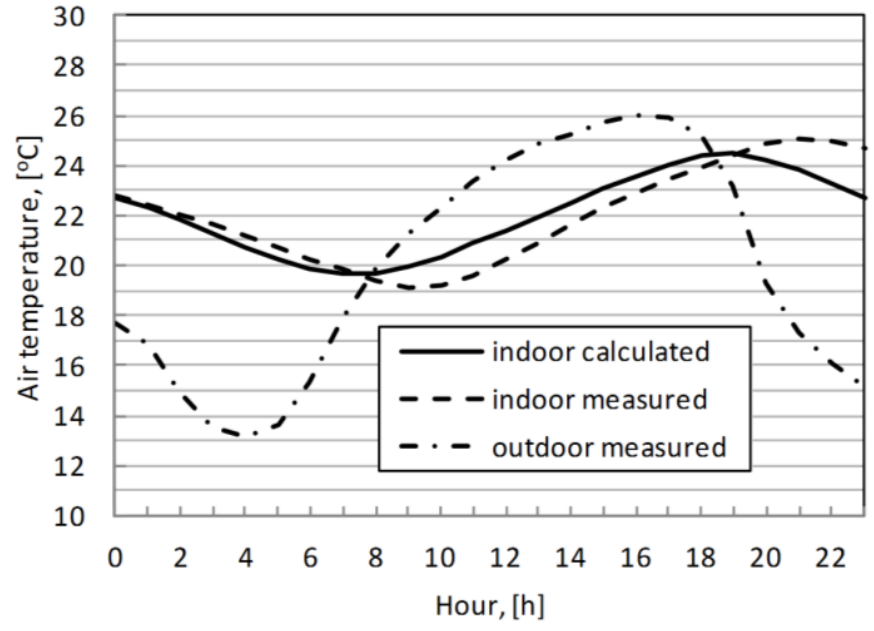

Figure 4. Air temperature variation. 


\section{Test box with a transparent area}

After a series of measurements was performed using the blinded test box, a window was installed. Subsequently, the air tightness of the test box was reconfirmed via the aforementioned blower door instrument. Convinced that no air change existed between the test box and the external environment, measurements were performed while maintaining no ventilation within the test area. The duration of the measurements for one orientation was one week in every month of the year. Using the solar radiation and external temperature data provided by the Agro-Meteorological Observatory as input parameters, based on the method given by EN ISO 13790, the indoor temperature variation was calculated and compared with the measured values for the N, S, E and W orientations of the glazed area.

In Figure 5, the temperature variation is shown for the South orientation of the glazed area.

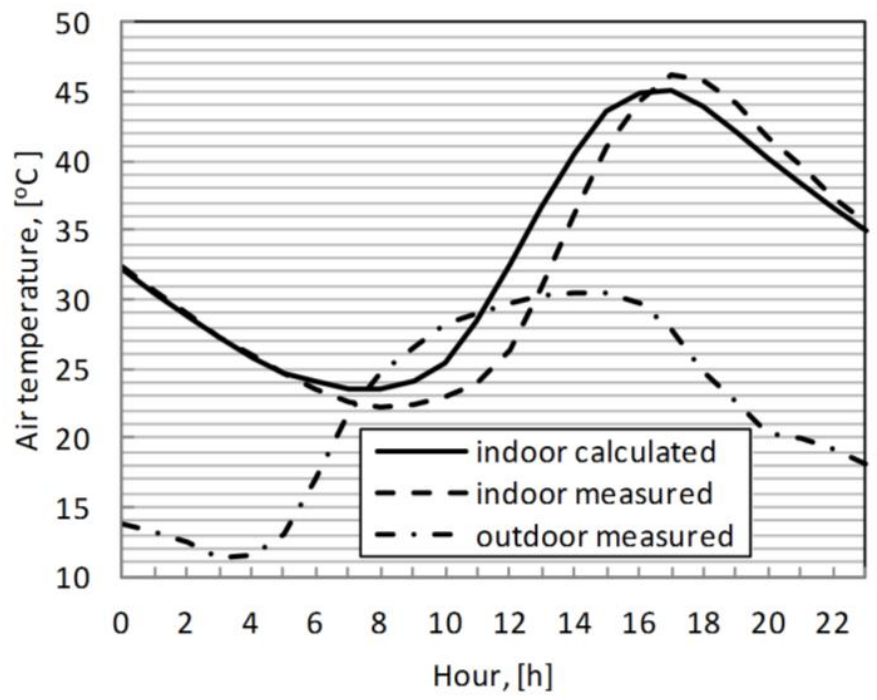

Figure 5. Temperature variation for the South orientation of the glazed area.

\section{Test box with transparent area and supplemental thermal mass}

The next step of this research studied a changed thermal mass of the test box. On the floor of the box, a 20-cm-thick sand layer was laid down. The density of the sand was $\rho=1600$ $\left[\mathrm{kg} / \mathrm{m}^{3}\right]$, the thermal conductivity was $\lambda=0.58[\mathrm{~W} / \mathrm{mK}]$ and the specific heat was $\mathrm{c}=840$ $[\mathrm{J} / \mathrm{kgK}]$. The temperature variation for East orientation of the glazed area is presented in Figure 6.

\section{Test box with transparent area and ventilation}

Due to the internal temperature variation for all orientations of the glazed area and the lack of air exchange, controlled mechanical ventilation was installed. On the wall where the window was installed, two pairs of orifices were mounted. At a height of $40 \mathrm{~cm}$ from the floor and a distance $40 \mathrm{~cm}$ from the side walls, two $\Phi 100 \mathrm{~mm}$ inlet orifices were placed; on the same wall, at $20 \mathrm{~cm}$ from the ceiling and $40 \mathrm{~cm}$ from the side walls, two $\Phi 100 \mathrm{~mm}$ orifices were fabricated for air exhaust. Axial ventilators were placed in these orifices: two below for fresh air and two above for exhausted air. The ventilators were chosen and 
controlled to ensure a $1.0\left[\mathrm{~h}^{-1}\right]$ air change rate $(\mathrm{ACH})$ in the test room. The measurements were initially taken without any supplementary thermal mass for each orientation of the glazed area (Figure 7).

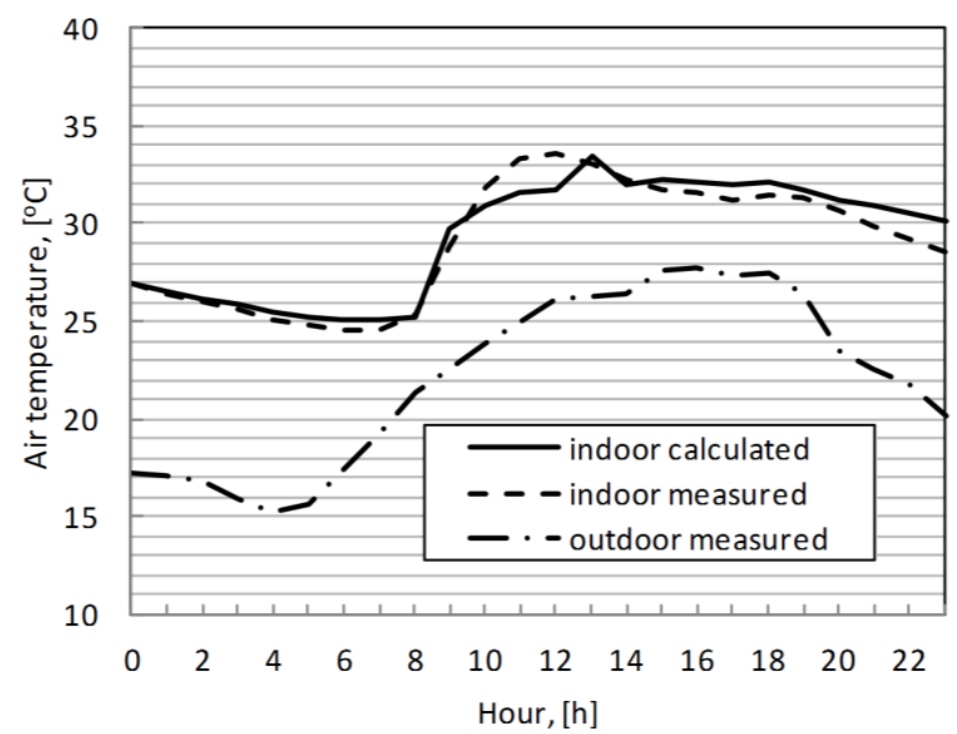

Figure 6. Temperature variation for the East orientation of the glazed area.

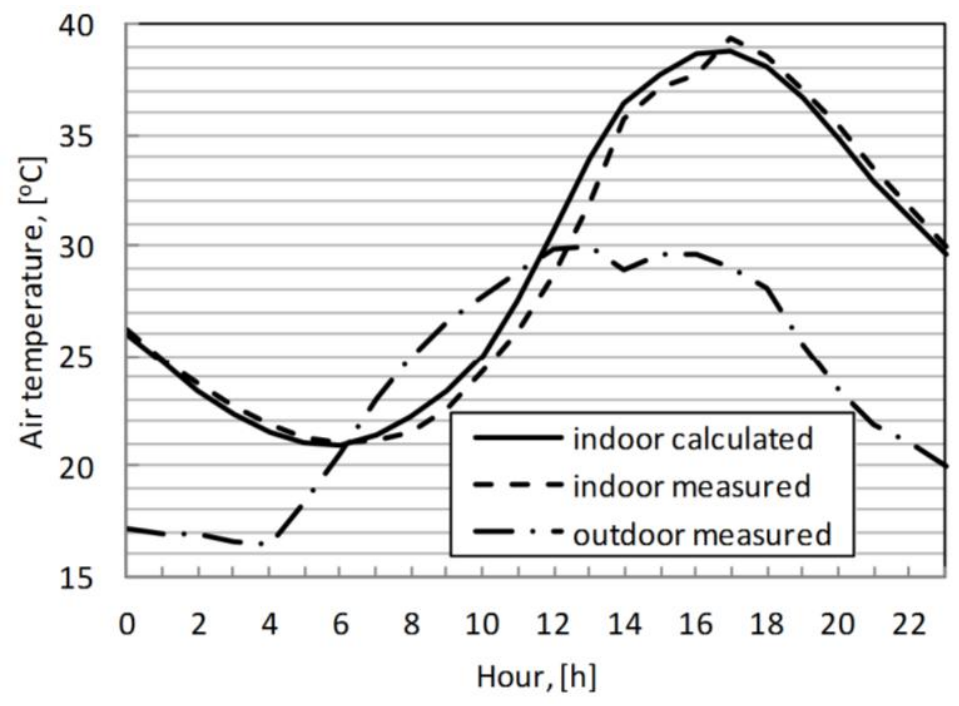

Figure 7. Temperature variation for the South orientation of the glazed area.

Test box with transparent area, ventilation and supplementary thermal mass

Laying the $20 \mathrm{~cm}$ of sand $\left(\rho=1600\left[\mathrm{~kg} / \mathrm{m}^{3}\right], \lambda=0.58[\mathrm{~W} / \mathrm{mK}], c=840[\mathrm{~J} / \mathrm{kgK}]\right)$ on the floor, the thermal mass of the test box was further changed. The temperature variation in the test box for the East orientation of the glazed area is presented in Figure 8 . 


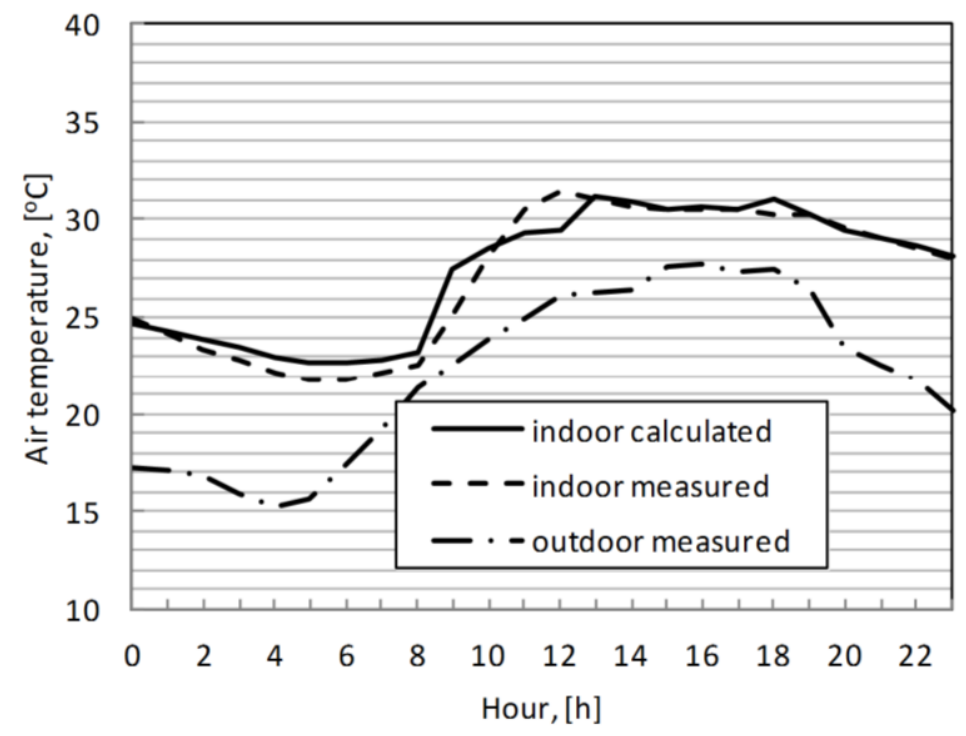

Figure 8. Temperature variation for the East orientation of the glazed area.

\section{Discussion}

By analyzing the calculated and measured indoor temperatures for different orientations of the glazed area, diverse ACHs and the thermal mass of the test room, it can be stated that the differences between calculated and measured daily mean indoor temperature values are between $+0.26 \mathrm{~K}$ and $+0.89 \mathrm{~K}$. Taking into account the accuracy of measuring instruments, it was considered that the analytical model given by ISO 13790 is appropriate for use in cooling energy calculations. The aim of the following analysis was to determine the effects of the thermal mass, orientation of the glazed area and air change rate on the indoor temperature and energy need for cooling.

Using the meteorological data for five consecutive years (2009-2013), this study identified the heat waves during each year, separately, for May, June, July and August. For temperature and energy calculations, the highest external temperatures and solar radiations were used. Assuming a $4.0 \times 4.0 \times 2.8 \mathrm{~m}$ corner room (with two external walls) that was placed on third level of a building, with a flat roof and a window built into one of external walls ( $150 \times 150 \mathrm{~cm}, 85 \%$ glazing), an indoor temperature and cooling energy analysis was completed. The calculations were performed for the aforementioned months to determine the varying orientations of the glazed area (no shading was considered), thermal masses and ACHs. The analyzed wall structures are as follows: masonry construction from fired clay brick (referred to as simply brick), autoclaved aerated concrete (AAC) and steel framed lightweight structure with mineral wool (referred to as light). In each case, the overall heat transfer coefficients of the external structures are equal to the requirements: $\mathrm{U}_{\text {wall }}=0.24 \mathrm{~W} / \mathrm{m}^{2} \mathrm{~K}, \mathrm{U}_{\text {roof }}=0.17 \mathrm{~W} / \mathrm{m}^{2} \mathrm{~K}, \mathrm{U}_{\text {window }}=1.0 \mathrm{~W} / \mathrm{m}^{2} \mathrm{~K}$.

The internal heat gains depended on the building's function (e.g., residential, office, educational) and the building users' habits. In this analysis, only solar gains were considered.

In Figure 9, the heat gains/losses by radiation are presented for the analyzed months and for different orientations of the glazed area. 

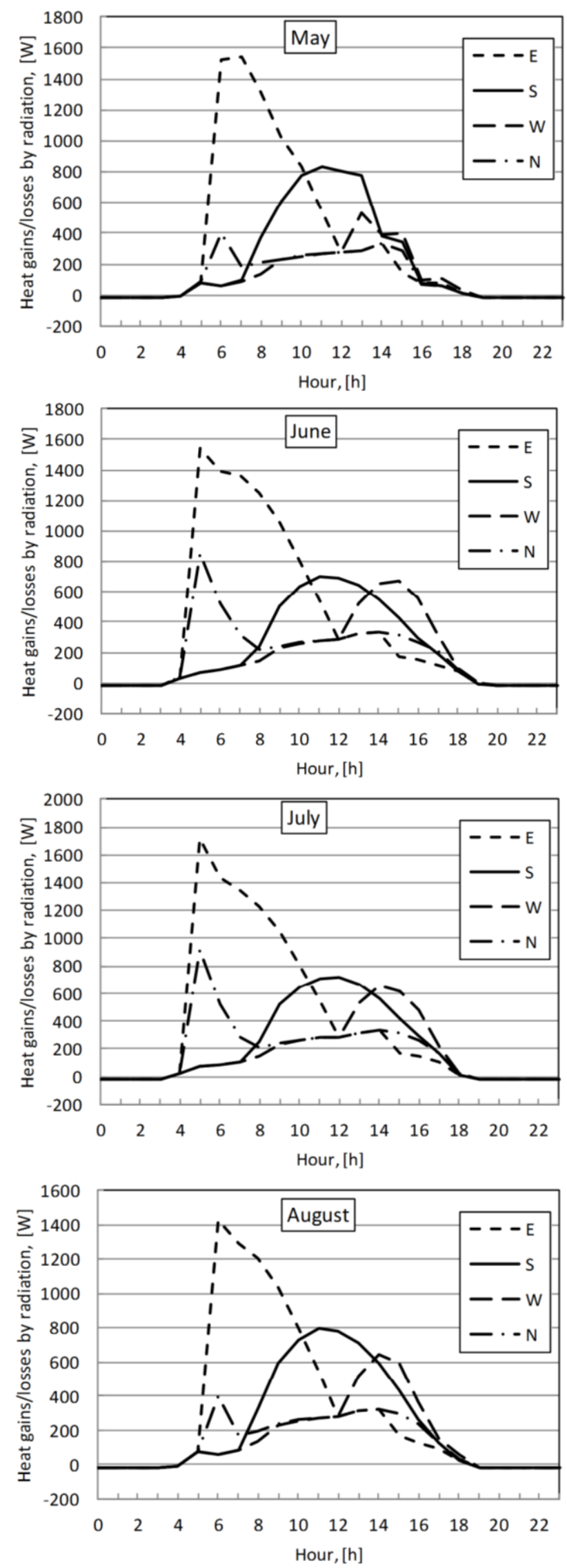

Figure 9. Heat gains/losses by radiation in different months. 
It can be observed that the highest solar gains are registered in July for the East orientation of the glazed area. Measurements had proven that the global radiation energy yield is asymmetric during a day. In the morning can be even double that in the afternoon. This is caused mainly by the cloudiness, aerosol and humidity concentration. During the analyzed months, these factors reduced in a greater amount the incident solar energy in the afternoon than in the first half of the day.

In Figure 10, the indoor air temperature variation is shown in July, in the case of the brick structure $\left(\mathrm{ACH}=0.5 \mathrm{~h}^{-1}\right)$, for different orientations of the glazed area.

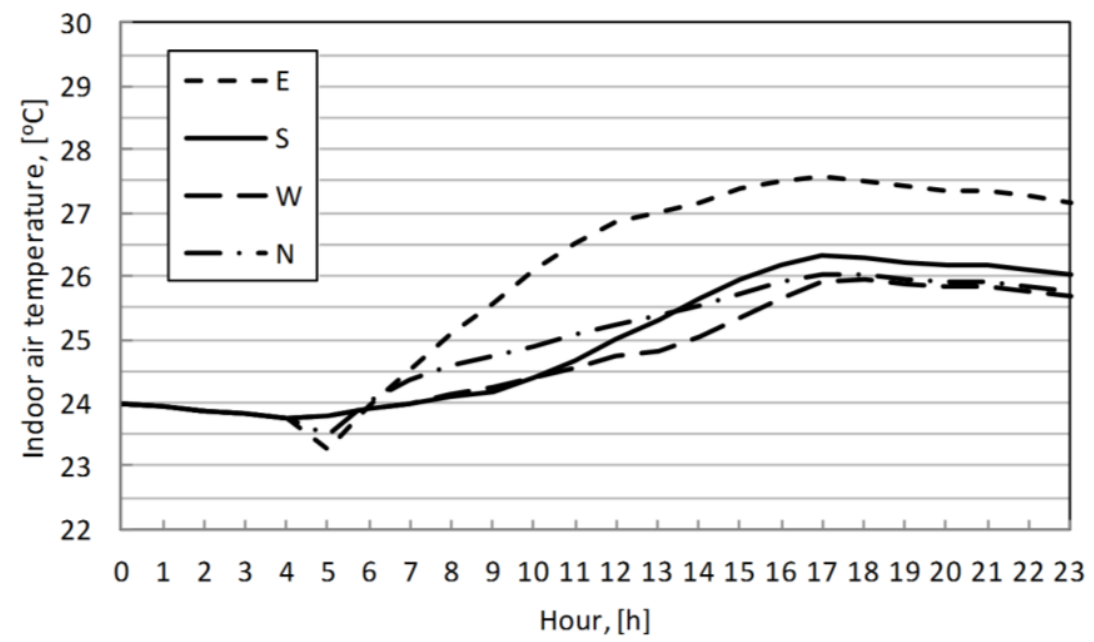

Figure 10. Indoor air temperature variation for different orientations of the glazed area.

In Figure 11, the indoor air temperature is illustrated during July for the East orientation of the glazed area $\left(\mathrm{ACH}=0.5 \mathrm{~h}^{-1}\right)$ and for different building structures.

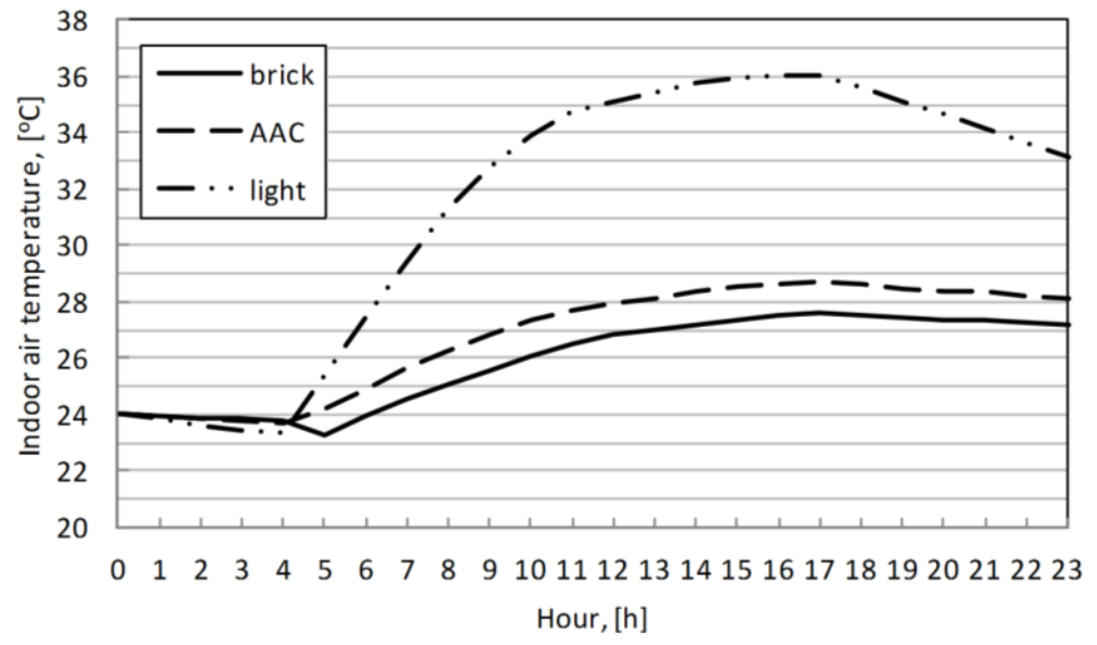

Figure 11. Indoor air temperature variation for different building structures.

In Figure 12, the indoor air temperature is presented for July for the East orientation of glazed area for different building structures and ACHs (without any cooling of the airflow). 


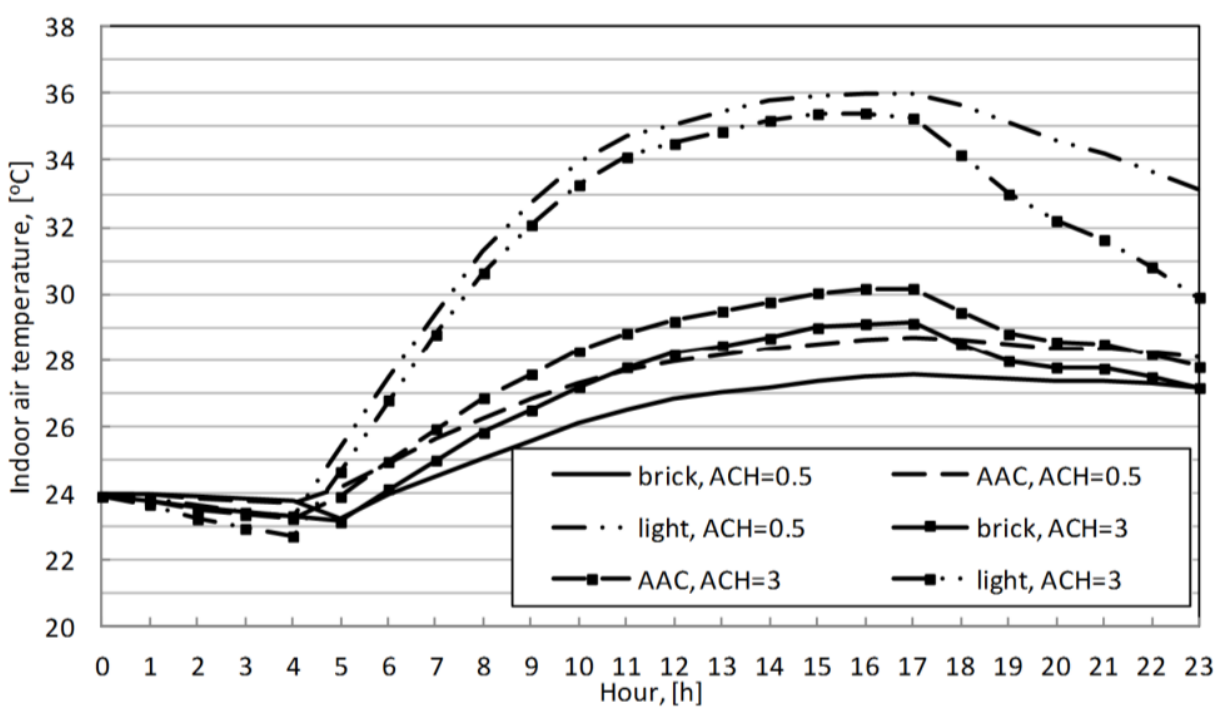

Figure 12. Indoor air temperature variation for different building structures and different ACHs.

It can be observed that the effect of the airflow increase is changed for the analyzed structures. In the case of lightweight structures, a higher ACH helps reduce the indoor air temperature; however, a higher $\mathrm{ACH}$ has a negative effect in the cases of both the AAC and the brick structures because the indoor air temperatures increase. Figure 13 shows the variation of temperature reduction or increase $\left(\Delta t_{\mathrm{i}}=t_{\mathrm{i}(\mathrm{ACH}=3)}-t_{\mathrm{i}}(\mathrm{ACH}=0.5)\right)$ caused by air change rate increase (from $0.5 \mathrm{~h}^{-1}$ to $3 \mathrm{~h}^{-1}$ ) for the analyzed structures and the East orientation of the glazed area.

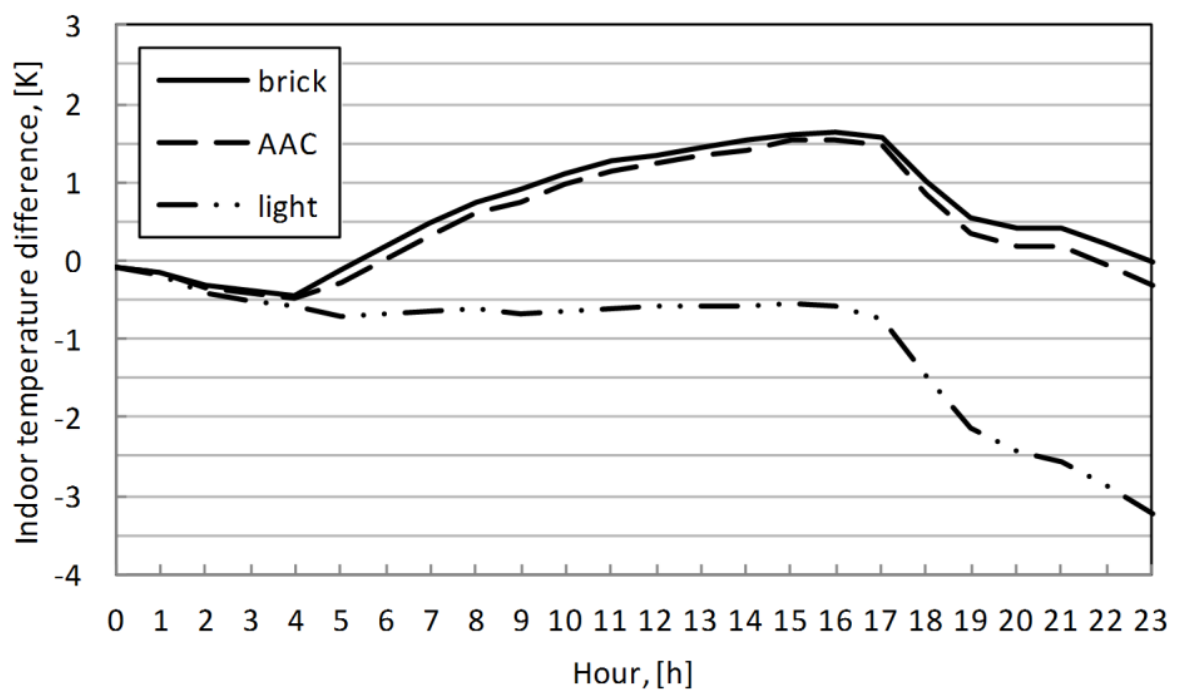

Figure 13. Indoor temperature difference obtained by increasing the $\mathrm{ACH}$ from $0.5 \mathrm{~h}^{-1}$ to 3 $\mathrm{h}^{-1}$. 
In order to analyze the effects of air change rate, orientation of glazed elements and thermal mass on the cooling energy use, calculations were carried out according to EN ISO 13790:2008, 2008. Based on the five-year hourly temperature values, the degree-day curve for cooling was extrapolated. Using the methodology given by Standard EN ISO 13790 and assuming a $26{ }^{\circ} \mathrm{C}$ operative temperature in the room, the energy required for cooling was determined as a function of the orientation of the glazed area, building structure and ACH. The cooling need is, (EN ISO 13790:2008, 2008):

$$
\phi_{H C, n d, u n}=\frac{\phi_{H C, n d 10}\left(\theta_{a i r, s e t}-\theta_{a i r, 0}\right)}{\left(\theta_{a i r, 10}-\theta_{a i r, 0}\right)}
$$

where:

$$
\phi_{H C, n d 10}=10 A_{f}
$$

where: $A_{f}$ is the conditioned area, $\left[\mathrm{m}^{2}\right], \theta_{\text {air }, 10}-$ is the air temperature obtained for a heating power of $10 \mathrm{~W} / \mathrm{m}^{2}, \theta_{\text {air }, 0}$ - is the air temperature in free floating conditions.

The air temperature $\left(\theta_{\text {air,set }}\right)$ needed to obtain the needed operative temperature is obtained using eq. (9), (EN ISO 13790:2008, 2008):

$$
\theta_{o p}=0,3 \theta_{\text {air }, \text { set }}+0,7 \theta_{s}
$$

The daily energy need for cooling obtained for analyzed room, in case of the typical days with incident radiation presented in Figure 9, are presented in Table 1.

Table 1. Cooling energy need, [Wh].

\begin{tabular}{lllllll}
\hline ACH & Orientation & Structure & May & June & July & August \\
\hline 0.5 & South & Light & 9595 & 12993 & 14406 & 15839 \\
& & Brick & 324 & 1920 & 2456 & 3245 \\
& AAC & 2256 & 4405 & 5179 & 6157 \\
\cline { 3 - 7 } & North & Light & 4248 & 11999 & 13544 & 10454 \\
& Brick & 0 & 1196 & 1647 & 989 \\
& & AAC & 0 & 3418 & 4118 & 2969 \\
\hline East & Light & 17805 & 26721 & 28918 & 23549 \\
& & Brick & 3155 & 7468 & 8448 & 6306 \\
& & AAC & 6609 & 12148 & 13381 & 10399 \\
\cline { 3 - 7 } & West & Light & 4401 & 10673 & 11056 & 11180 \\
& & Brick & 0 & 1094 & 1295 & 1482 \\
& & AAC & 4 & 3028 & 3375 & 3578 \\
\hline 3.0 & South & Light & 10869 & 21202 & 24312 & 27997 \\
& & Brick & 1003 & 6075 & 7383 & 9691 \\
& & AAC & 3070 & 9842 & 11510 & 14190 \\
\hline
\end{tabular}




\begin{tabular}{llllll}
\hline North & Light & 4984 & 19096 & 22369 & 21475 \\
& Brick & 0 & 5248 & 6551 & 6671 \\
& AAC & 479 & 8761 & 10362 & 10269 \\
\hline East & Light & 17731 & 34574 & 38589 & 35381 \\
& Brick & 3984 & 13233 & 14976 & 13922 \\
& AAC & 7353 & 18708 & 20806 & 19187 \\
\hline West & Light & 5405 & 18667 & 20582 & 22678 \\
& Brick & 0 & 4513 & 5431 & 6991 \\
& AAC & 561 & 7897 & 9131 & 10848 \\
\hline
\end{tabular}

Analyzing the obtained cooling energy demand values it can be observed that there are huge differences between the energy need for cooling values depending on the orientation of transparent area, used building material (thermal mass) and air change rate. Increasing the thermal mass lower cooling need will be obtained. West and South orientations of the transparent elements will give a lower cooling demand than East orientation. In case of East orientation to reduce the huge amount of cooling need proper shading elements are needed. If the air change rate is constant, it is better to use lower ACH values. The higher $\mathrm{ACH}$ will reduce the cooling energy demand only in case of light structure. Taking as reference the energy demand obtained for brick structure it can be observed, that for light structure the obtained cooling need can be even nine times higher. For AAC the cooling need is higher than in case of brick structure but the differences are between $30 \%-125 \%$, depending on the orientation of transparent area and adopted air change rate.

\section{Conclusions}

The PASSOL laboratory permits the measurement of indoor air temperatures for different orientations of the glazed area. Measurements carried out from 2009 to 2013 have proven that the methodology given by EN ISO 13790 provides appropriate values of indoor air temperatures in the test box at various air change rates and thermal mass values. Calculations have further proven that the East orientation of the glazed area is the most disadvantageous in the summer period if shading elements are not used. Comparing three different structures, it is clear that the energy required for cooling can be reduced by significantly, if the thermal mass and the air change rate are properly chosen for a given orientation of transparent area.

We would like to continue our research related to summer heat load in buildings with the investigation of the effects of shadowing of transparent elements and cost-energy analysis of various technological solutions which allows the reduction of overheating.

\section{Acknowledgments}

This work is supported by the TÁMOP-4.2.2.A-11/1/KONV-2012-0041 project. The project is co-financed by the European Union and the European Social Fund.

The authors would like to express their gratitude to the Agro-Meteorological Observatory, Debrecen, for providing indispensable meteorological data. 


\section{References}

Blondeau P, Spérandio M and Allard F (1997) Night ventilation for building cooling in summer. Solar Energy 61(5): 327-335.

Breesch H, Bossaer A and Janssens A (2005) Passive cooling in a low-energy office building. Solar Energy 79(6): 682-696.

Corgnati SP and Kindinis A (2007) Thermal mass activation by hollow core slab coupled with night ventilation to reduce summer cooling loads. Building and Environment 42(9): 3285-3297.

EN ISO 13790:2008 (2008) Energy performance of buildings - Calculation of energy use for space heating and cooling.

Geros V, Santamouris M, Karatasou S, et al. (2005) On the cooling potential of night ventilation techniques in the urban environment. Energy and Buildings 37(3): 243257.

Geros V, Santamouris M, Tsangrasoulis A, et al. (1999) Experimental evaluation of night ventilation phenomena. Energy and Buildings 29(2): 141-154.

Larsen TS and Heiselberg P (2008) Single-sided natural ventilation driven by wind pressure and temperature difference. Energy and Buildings 40(6): 1031-1040.

Leather Ph, Pyrgas M, Beale D, et al. (1998) Windows in the workplace: sunlight, view, and occupational stress. Environment and Behavior 30(6): 739-762.

Luterbacher J, Dietrich D, Xoplaki E, et al. (2004) European seasonal and annual temperature variability, trends, and extremes since 1500. Science 303(5663): 1499 -1503 .

Pfafferott JÜ, Herkel S, Kalz DE, et al. (2007) Comparison of low-energy office buildings in summer using different thermal comfort criteria. Energy and Buildings 39(7): 750-757.

Schär Ch, Vidale PL, Lüthi D, et al. (2004) The role of increasing temperature variability in European summer heatwaves. Nature 427(6972): 332-336.

Shaviv E, Yezioro A, Capeluto IG, et al. (2001) Thermal mass and night ventilation as passive cooling design strategy. Renewable Energy 24(3-4): 445-452.

Stone NJ (1998) Windows and environmental cues on performance and mood. Environment and Behavior 30(3): 306-321.

Voss K, Herkel S, Pfafferott J, et al. (2007) Energy efficient office buildings with passive cooling - results and experiences from a research and demonstration programme. Solar Energy 81(3): 424-434.

Yang L and Li Y (2008) Cooling load reduction by using thermal mass and night ventilation. Energy and Buildings 40(11): 2052-2058.

Zhou J, Zhang G, Lin Y, et al. (2008) Coupling of thermal mass and natural ventilation in buildings. Energy and Buildings 40(6): 979-986. 